\title{
Wind Turbines Emulating Inertia and Supporting Primary Frequency Control
}

\author{
Johan Morren, Student Member, IEEE, Sjoerd W. H. de Haan, Member, IEEE, Wil L. Kling, Member, IEEE, and \\ J. A. Ferreira, Fellow, IEEE
}

\begin{abstract}
The increasing penetration of variable-speed wind turbines in the electricity grid will result in a reduction of the number of connected conventional power plants. This will require changes in the way the grid frequency is controlled. In this letter, a method is proposed to let variable-speed wind turbines emulate inertia and support primary frequency control. The required power is obtained from the kinetic energy stored in the rotating mass of the turbine blades.
\end{abstract} tion.

Index Terms-Frequency control, stability, wind power genera-

\section{INTRODUCTION}

$\mathbf{T}$ HE NUMBER of wind turbines connected to the grid is steadily increasing, and some countries, such as Denmark, have high penetration levels of wind turbines already.

Nowadays, the grid frequency is controlled by the conventional power plants. The goal of the control is to keep the frequency within specified limits. To obtain this, conventional generators are equipped with so-called primary and secondary control. Further, the inertia in the grid limits the rate of frequency change in case of an unbalance between generated and consumed power.

Contribution of wind farms to primary frequency control is nowadays required by several grid operators [1] but will be difficult to realize as the energy source (wind) is not directly controllable. So far, only one method has been proposed to meet this requirement, where the wind turbines do not supply the maximum available power in normal situation, so that a margin remains for power control [2].

Similar to conventional generators, wind turbines have a significant amount of kinetic energy stored in the rotating mass of their blades. In case of variable-speed wind turbines, this energy will not contribute to the inertia of the grid as the rotational speed is decoupled from the grid frequency by a power electronic converter. In this letter, additional control is proposed that makes the "hidden inertia" available to the grid. In this way, wind turbines can 1) emulate inertia and 2) support the primary frequency control for some time.

\section{WIND TURBINE INERTIA}

The proposed methods use the kinetic energy stored in the rotating mass of the wind turbine, which is given by

$$
E=\frac{1}{2} J \omega_{w}^{2}
$$

Manuscript received June 20, 2005; revised August 24, 2005. This work was funded in part by SenterNovem within the Program IOP-EMVT. Paper no. PESL-00056-2005.

J. Morren, S. W. H. de Haan, and J. A. Ferreira are with the Electrical Power Processing Unit, Delft University of Technology, 2628CD Delft, The Netherlands (e-mail: J.Morren@ewi.tudelft.nl).

W. L. Kling is with the Electrical Power Systems Group, Delft University of Technology, 2628CD Delft, The Netherlands.

Digital Object Identifier 10.1109/TPWRS.2005.861956

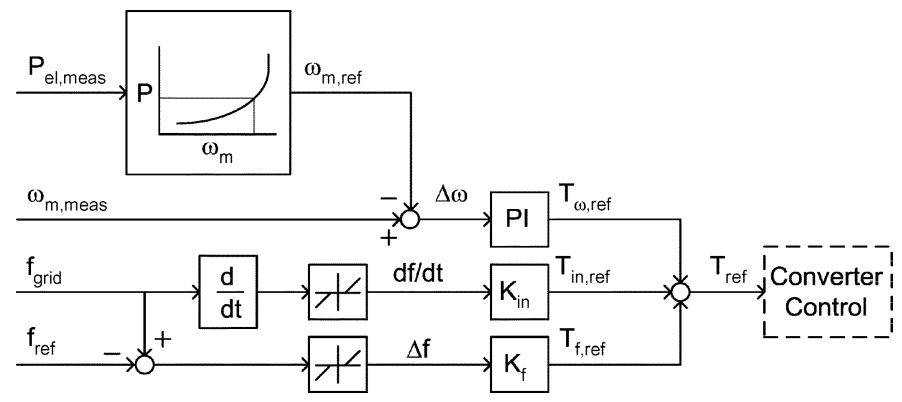

Fig. 1. Proposed controller. Upper branch: wind rotor control. Middle branch: inertia emulation. Lower branch: frequency control support.

with $J$ the inertia of the wind rotor and $\omega_{w}$ its rotational speed. In electrical power engineering, often the so-called inertia constant $H$ is used

$$
H=\frac{E}{S}=\frac{J \omega_{w}^{2}}{2 S}
$$

where $S$ is the nominal apparent power. The inertia constant has the dimension time and gives an indication of the time duration that the generator can provide nominal power by only using its kinetic energy. Typical inertia constants for the generators of the large power plants are in the range of 2-9 s [3]. Typical values for wind turbines have roughly the same value: about $2-6$ $\mathrm{s}$ [4]. This implies that introduction of wind turbines in the grid does not necessarily reduce the amount of kinetic energy that is available. Additional control is proposed to emulate inertia and to support primary frequency control.

\section{PROPOSED CONTROLleR}

Normally, the controllers of variable-speed wind turbines try to keep the turbine at its optimal speed in order to produce maximum power. The controller gives a torque set point that is based on measured speed and power (see Fig. 1).

The torque set point is an input for the converter control that realizes the torque by controlling the generator currents. An additional controller is proposed that adapts the torque set point as a function of the deviation of the grid frequency $\Delta f$ and of the rate of the change of the grid frequency $d f / d t$ (see Fig. 1). The emulated inertia is proportional to the controller constant $K_{i n}$, and the support to primary frequency control is proportional to $K_{f}$, where this latter loop is activated when the grid frequency exceeds certain limits.

\section{Simulation SeT-UP}

Simulations have been done only to show the ability of wind turbines to support primary frequency control. In this example, no extra inertia is emulated.

A model of a small grid has been used. It consists of two synchronous generators (20 and $80 \mathrm{MW}$ ), an aggregated load (120 MW), and six variable-speed DFIG wind turbines (2.75 MW each), as described in [5]. Only one of the turbines is simulated; its output current is multiplied by six. 


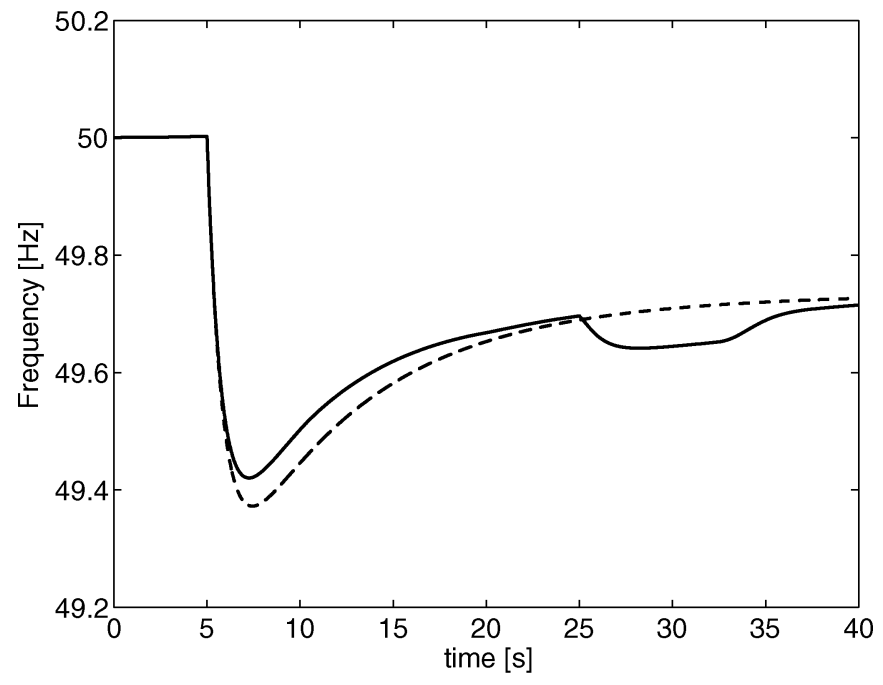

(a)

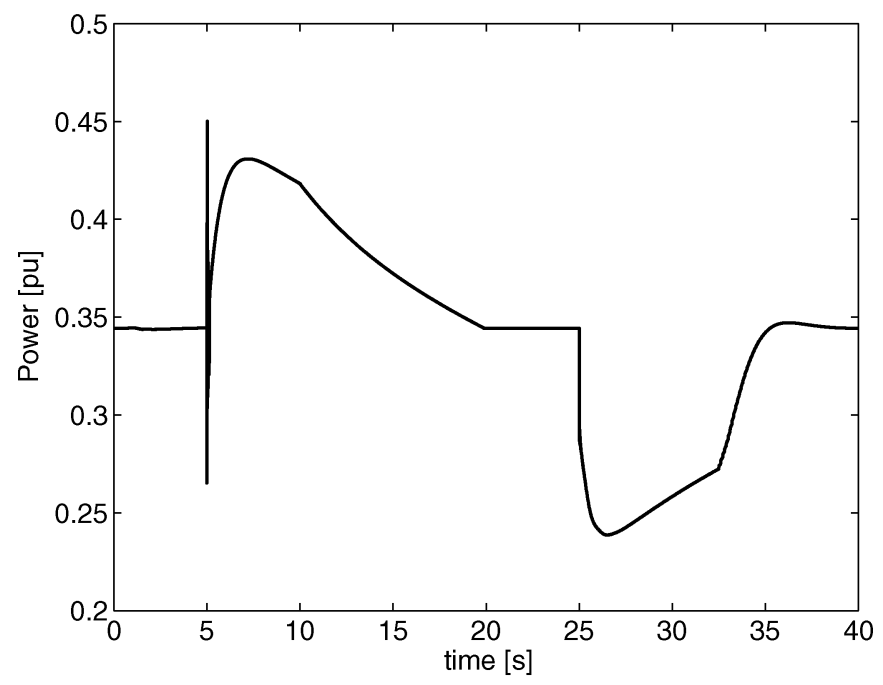

(b)

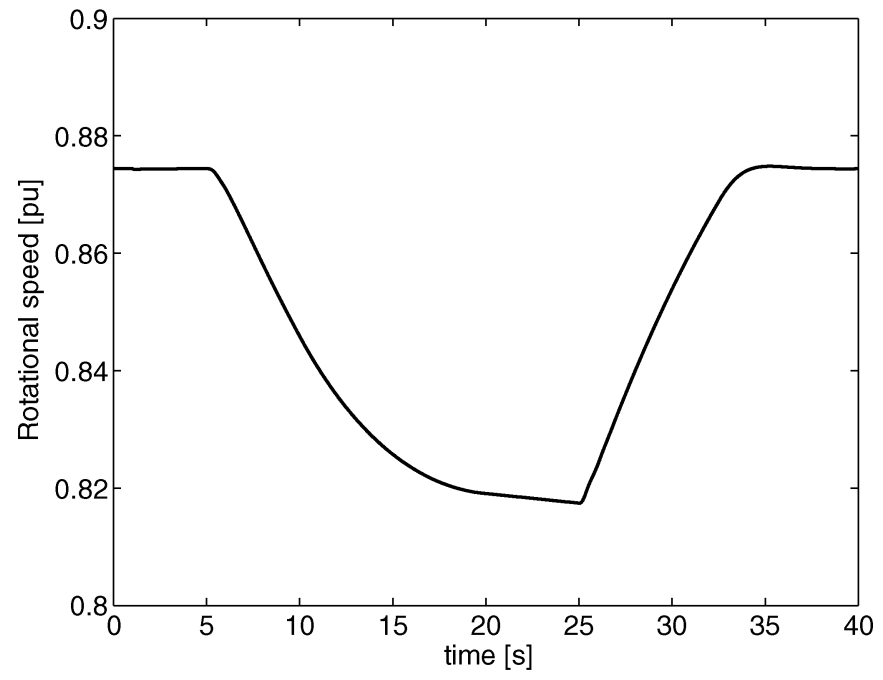

(c)

Fig. 2. Response to disconnection of synchronous generator with controller ON (solid) and controller OFF (dashed). (a) Grid frequency. (b) Wind turbine power. (c) Wind turbine rotational speed.
An event is simulated in which the synchronous generator of $20 \mathrm{MW}$ is suddenly disconnected at $\mathrm{t}=5 \mathrm{~s}$. This results in a change in frequency. The rate of frequency change depends, amongst others, on the system inertia.

In Fig. 2, simulations are shown with controller OFF (dashed lines) and controller ON (solid line). Fig. 2(a) shows that the initial response is the same for both cases. When the frequency limit of $49.9 \mathrm{~Hz}$ is exceeded, the f-support controller is activated, resulting in a slightly higher frequency than can be realized with controller OFF.

Fig. 2(b) shows the output power of the wind turbine. It increases at the moment that the frequency exceeds its limit and the controller is activated. Because kinetic energy from the wind turbine is used to supply more power to the grid, the rotational speed of the turbine is decreasing [see Fig. 2(c)]. The turbine resumes normal operation at $\mathrm{t}=25 \mathrm{~s}$. At this moment, the power drops to a value that is much lower than its initial value, because the turbine is not at its optimal speed anymore. In addition, power is needed to speed the turbine up to its optimal operation speed, which implies that only a part of the available aerodynamic power is transmitted to the grid. The drop in power also explains why the frequency curves in Fig. 2(a) are different from each other after $\mathrm{t}=\sim 25 \mathrm{~s}$.

\section{DISCUSSION AND CONCLUSION}

Fig. 2(a) shows that the wind turbine operated at only 0.35 p.u. The additional power that was generated for support was roughly 0.1 p.u. The ability of the wind turbine to support the primary frequency control will be better at higher power, because the kinetic energy stored in the blades will increase.

During the support, the rotational speed of the wind turbine is decreasing. As a result, the power will drop considerable when the frequency control support is ended, as shown in Fig. 2(b). This drop in power will be undesirable mostly, especially when complete wind farms show this behavior. In larger wind farms, the effect can be mitigated partially by ending the frequency control support of the turbines at different times. Also a gradual change to normal operation, instead of the abrupt change that is applied in the example, will improve the behavior.

The main conclusion that can be drawn from the results in this letter is that variable-speed wind turbines are able to support primary frequency control and to emulate inertia by applying additional control loops. For that purpose, the kinetic energy stored in the "hidden inertia" of the turbine blades is used.

\section{REFERENCES}

[1] J. Matevosyan, T. Ackermann, and S. Bolik, "Technical regulations for the interconnection of wind farms to the power systems," in Wind Power in Power Systems, T. Ackermann, Ed. Chicester, U.K.: John Wiley, 2005, pp. 115-142.

[2] P. Soerensen, A. D. Hansen, K. Thomsen, H. Madsen, H. A. Nielsen, N. K. Poulsen, F. Iov, F. Blaabjerg, and M. H. Donovan, "Wind farm controllers with grid support," in Proc. 5th Int. Workshop Large-Scale Integration Wind Power Transmission Networks Offshore Wind Farms, Glasgow, U.K., Apr. 7-8, 2005.

[3] J. J. Grainger and W. D. Stevenson, Power System Analysis. New York: McGraw-Hill, 1994.

[4] H. Knudsen and J. N. Nielsen, "Introduction to the modeling of wind turbines," in Wind Power in Power Systems, T. Ackermann, Ed. Chicester, U.K.: Wiley, 2005, pp. 525-585.

[5] J. T. G. Pierik, J. Morren, E. Wiggelinkhuizen, S. W. H. de Haan, T. G. van Engelen, and J. Bozelie, "Electrical and control aspects of offshore wind turbines II (Erao-2),", Tech. Rep. ECN-C- -04-050, vol. 1, Dynamic models of wind farms, Jun. 2004. 